\title{
Binding, tuning and mechanical function of the 4-hydroxy-cinnamic acid chromophore in photoactive yellow protein
}

\author{
Received 23rd January: 2007, Accepted 8th March 2007 \\ First published as an Advance Article on the web 19th March 2007 \\ DOI: $10.1039 / \mathrm{b} 701072 \mathrm{a}$
}

Michael A. van der Horst, ${ }^{*}$ Jos C. Arents, Remco Kort $\uparrow$ and Klaas J. Hellingwerf

The bacterial photoreceptor protein photoactive yellow protein (PYP) covalently binds the chromophore 4-hydroxy coumaric acid, tuning (spectral) characteristics of this cofactor. Here, we study this binding and tuning using a combination of pointmutations and chromophore analogs. In all photosensor proteins studied to date the covalent linkage of the chromophore to the apoprotein is dispensable for light-induced catalytic activation. We analyzed the functional importance of the covalent linkage using an isosteric chromophore-protein variant in which the cysteine is replaced by a glycine residue and the chromophore by thiomethyl-p-coumaric acid (TMpCA). The model compound TMpCA is shown to weakly complex with the $\mathrm{C} 69 \mathrm{G}$ protein. This non-covalent binding results in considerable tuning of both the $\mathrm{p} K_{\mathrm{a}}$ and the color of the chromophore. The photoactivity of this system, however, was strongly impaired, making PYP the first known photosensor protein in which the covalent linkage of the chromophore is of paramount importance for the functional activity of the protein in vitro. We also studied the influence of chromophore analogs on the color and photocycle of PYP, not only in WT, but especially in the E46Q mutant, to test if effects from both chromophore and protein modifications are additive. When the $\mathrm{E} 46 \mathrm{Q}$ protein binds the sinapinic acid chromophore, the color of the protein is effectively changed from yellow to orange. The altered charge distribution in this protein also results in a changed $\mathrm{p} K_{2}$ value for chromophore protonation, and a strongly impaired photocycle. Both findings extend our knowledge of the photochemistry of PYP for signal generation.

\section{Introduction}

Pigmented proteins that function as a receptor for visible light bind cofactors to acquire absorption in this region of the spectrum. The cofactors, in these cases called chromophores, usually are small organic molecules that bind to the apoprotein. The chromophores absorb UV and/or visible light because of the presence of a conjugated system like an aromatic ring or a polyene chain. The surrounding apoprotein is able to change the absorption properties of the chromophore through specific interactions, in order to obtain a holoprotein with the desired absorption characteristics. This phenomenon, called spectral tuning has been extensively studied in rhodopsins, ${ }^{1,2}$ and in photoactive yellow protein (PYP). ${ }^{3,4}$ PYP is a small, water-soluble photoreceptor protein first found in IIalorhodospira halophila. ${ }^{5}$ It absorbs maximally at $446 \mathrm{~nm}$, and after blue-light excitation it enters a fully reversible photocycle. During this cycle several short- and long-lived intermediates are formed, and ultimately the ground state is recovered in $\sim 0.5 \mathrm{~s}^{6,7}$ As a chromophore, PYP contains 4-hydroxy-cinnamic acid (also known as p-coumaric acid: pCA), covalently bound to the single cysteine of the protein through a thio-ester linkage. . $^{8-10}$ In the ground state of the protein, the phenolic oxygen of the chromophore is deprotonated, and the vinyl double bond is in its trans configuration (see Fig. 1). The negative charge on the

Laboratory for Molecular Microbial Physiology, Swammerdam Institute for Life Sciences. University of Amsterdam. Nieuwe Achtergracht 166, 1018 $W V$, Amsterdam, The Netheriands

†Present address: TNO Quality of Life, Department of Microbiology Utrechtseweg 48, 3704HE Zeist. The Netherlands. oxygen atom is stabilized by a hydrogen-bonding network that consists of Tyr42, Glu46, Thr50 and the chromophore. ${ }^{11}$ During the photocycle, the chromophore vinyl bond isomerizes, which is followed by protonation of the chromophore by its hydrogen bonding partner Glu46. ${ }^{12,13}$ An E46Q mutant, in which this proton-donor glutamic acid has been replaced by a glutamine residue, has been thoroughly studied. ${ }^{14-18}$ This E46Q mutant of PYP has retained its photoactivity, but has significantly altered characteristics: Its absorption maximum has been red-shifted to $460 \mathrm{~nm}$, and ground state recovery is $\sim 30$ times faster (at $\mathrm{pH} 8$ ) than that in WT PYP.

For all currently known photosensor protein families, apart from the $p$-coumaric acid-containing xanthopsin family, ${ }^{19}$ it has been shown that a covalent linkage of the chromophore to the apoprotein in the receptor state is not an essential prerequisite for catalytic activation. These families include the rhodopsins, phytochromes and flavin-containing photoreceptor proteius. ${ }^{20}$ In the flavin-containing photoreceptor proteins (cryptochromes, phototropins (and other-domain containing proteins) and BLUF proteins) FAD or FMN, is bound non-covalently to the apoprotein in the ground state. Note, however, that for the phototropin family, it has been shown that there is a transient covalent linkage from the FMN chromophore to a conserved cysteine residue in the signaling state. ${ }^{21.22}$ The rhodopsins comprise the protein family with members containing a seven-transmembrane helixcontaining apoprotein. A retinal is bound as the chromophore to a lysine residue in this apoprotein through a Schiff-base linkage. For both bacteriorhodopsin and visual rhodopsin it has been established, using site-directed mutagenesis, that functional 


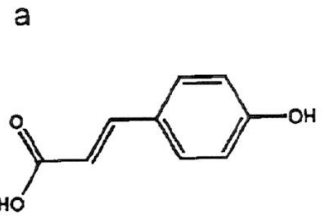

4-hydroxy-cinnamic acid (pCA)

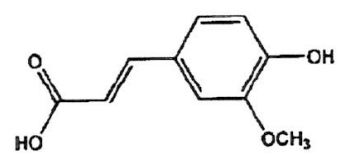

3-methoxy-4-hydroxycinnamic acid (fer)
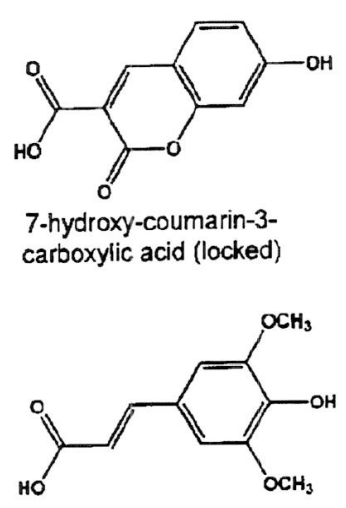

3,5-dimethoxy-4-hydroxycinnamic acid $(\sin )$

b<smiles>CNC(=O)C(CCC(=O)O)NC(C)=O</smiles>

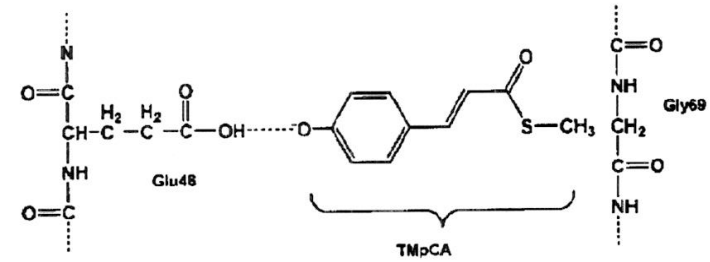

Fig. 1 Chemical structures of the chromophores used in this study. (a) pCA is the native chromophore in $H$. halophila PYP. The locked chromophore cannot undergo trans-cis isomerization. The fer chromophore has one methoxy-substitution on the meta-position of the aromatic ring, the sin chromophore has two. (b) Schematic representation of the chromophore-binding pocket in PYP and the model compound used in this study for isosteric replacement; upper part: wild type chromophore binding pocket, with the 4-hydroxy-cinnamic acid chromophore covalently bound to Cys69; lower part: the TMpCA model compound in the binding pocket of C69G PYP, thereby providing a situation of isosteric replacement compared to wild type protein.

holoprotein is obtained even in the absence of a covalent linkage: The covalent linkage between retinal and the backbone of the apoprotein is not required for the function of bacteriorhodopsin as a proton pump if proper isosteric replacement is provided, as shown in bothref. 23 and.ref. 24. In similar experiments Zhukovsky et al. showed that a covalent bond to the retinaldehyde in mammalian thodopsin is not essential for binding of the chromophore nor for catalytic activation of transducin. ${ }^{25}$ In the phytochromes, a linear tetrapyrole, usually covalently bound to a cysteine via a thiocther linkage, functions as the chromophore (for a review, see ref. 26). Recently, a subclass of bacteriophytochromes has been discovered, in which the chromophore is bound noncovalently ( $\mathrm{CphB}$ from Calothrix sp. $\left.\mathrm{PCC} 7601^{27}\right)$. Both the latter,

and vat phytochrome reconstituted with a chromophore analogue not able to bind covalently, were shown to be fully functional in vitro. ${ }^{28}$

Heterologous overexpression of apo-PYP in Escherichia coli allows us to attach chromophore derivatives to PYP in vitro. ${ }^{19}$ The spectral tuning and fluorescence properties of WT PYP, reconstituted with the native chromophore and several chromophore analogs, and in various PYP mutants, have been described..$^{3,29-33}$ In these studies, contributions to the color tuning of either amino acid residues in the chromophore-binding pocket, or of substituents on the aromatic ring of the chromophore, are described. The remarkable shift in absorption maximum-from $284 \mathrm{~nm}$ for free pCA in aqueous solvent to $446 \mathrm{~nm}$ in the chromophore-binding pocket in the protein-is caused by the joint contribution of: (i) formation of the thiol ester bond between pCA and Cys69, (ii) deprotonation of the chromophore, and (iii) specific proteinchromophore interactions. Still, the precise molecular origin of this shift remains a topic of interest. Here, we extend these analyses and study the combination of a point mutation and chromophore derivatives on the tuning and photocycle characteristics in PYP, to analyze the (combined) effects of changed electron density on the chromophore, and changed hydrogen-bonding between the chromophore and Glu46.

Furthermore, the functional importance of the covalent linkage between chromophore and apoprolein in PYP is studied by changing cysteine 69 to a glycine or an alanine residue. The addition of the methyl thio-ester of the pCA chromophore (methylmercaptyl4-hydroxycinnamate, also known as thiomethyl-p-coumaric acid, TMpCA) to C69G PYP results in a structure that is isosteric with the wild type holo protein. The only differences are the absence of the covalent linkage (see Fig. 1) and possibly changes in the flexibility of the protein backbone at that position. We describe the binding of this chromophore model compound to the apoprotein derivatives, as detected via the spectral tuning of the chromophore, and the resulting changes of spectroscopic properties of this system.

\section{Experimental}

\section{Sample preparation}

Apo-PYP, both of WT, E46Q-, C69A- and C69G-protein, was produced and isolated as described in ref. 19 as hexahistidine tagged apoprotein in Escherichia coli. Mutagenesis was performed using the QuickChange kit (Stratagene) and with pHISP as a template. ${ }^{19}$ The sequences of the mutagenic primers for C69G were: 5' GGCAAGAACTTCTTCAA GGACGTGGCCCCGGGCACTGACAGCC 3 and 5 GGCTGTCAGTGCCCGGGGCC AGCTCCTTGAAGAAGTTCTTGCC 3 and for C69A: 5 CTTCAAGGACGTCGCCC CG GCCACTGACAGCCCGG $3^{\prime}$ and $5^{\prime}$ CCGGGCTGTCAGTGGCCGGGGCGACGTCCTTGAAG $3^{\prime}$. The mutations were confirmed by nucleotide sequence analysis. Except for the $\mathrm{C} 69$ variants, the apoprotein was reconstituted with the 1,1-carbonyldiimidazole derivative of the respective chromophore (i.e 4-hydroxy-cinnamic acid (pCA), 7-hydroxy-coumarin-3-carboxylic acid (locked), 3-methoxy-4hydroxycinnamic acid (ferulic acid; fer) or 3,5-dimethoxy-4hydroxy-cinnamic acid (sinapinic acid; $\sin$ ), sec also Fig. 1) as described in ref. 34. Protein samples were used without removal of 
their hexahistidine containing $N$-terminal tag in $10 \mathrm{mM}$ Tris- $\mathrm{HCl}$, $\mathrm{pH} 8.0$.

\section{Chromophore synthesis}

4-Hydroxy-cinnamic acid derivatives with modifications on the phenolic part of the chromophore were synthesized as described in ref. 3. Thiomethylesters were synthesized from both $p$ coumaric acid (Sigma) and 7-hydroxy-coumarin-3-carboxylic acid (Molecular Probes), resulting in TMpCA and TM7HC, respectively. They were synthesized using the 1,1-carbonyldimidazole (Aldrich) derivative of the chromephores (prepared as described in ref. 34) and sodiumthiome thoxide (Acros Organics). An equimolar amount of sodiumthiomethoxide (dissolved in water) was added to the activated ester of the chromophore and the mixture was allowed to react overnight at room temperature. The compound was then purified using a silicagel column. The column was washed with 2 column volumes petroleum ether, after which the thio-methyl ester was eluted using a 1:1 ethylacetate-petroleum ether mixture. Concentrated TMpCA samples were stored in dry $N, N$-dimethylformamide (DMF). The identity and purity of the compounds was confirmed using NMR and mass spectrometry. The extinction coefficient of TMpC $\Lambda$ was determined using high$\mathrm{pH}$ hydrolysis of the thiocster; the compound was dissolved in $10 \mathrm{mM}$ phosphate, $\mathrm{pH} 13$ and stirred for $30 \mathrm{~min}$, after which no further spectral changes were observed. After hydrolysis the $\mathrm{pH}$ was lowered to 5 and the spectrum was compared to the spectrum of $p$-counaric acid at $\mathrm{pH} 5$, which has a molar extinction coeflicient $(\varepsilon)$ of $20 \mathrm{mM}^{-1} \mathrm{~cm}^{-1}$ in its protonated form. ${ }^{35}$

\section{Steady-state and transient (millisecond-second) UV/Vis measurements}

Steady-state protein spectra and photocycle kinetics on a millisecond to second time-scale were measured with an $\mathrm{HP} 8453 \mathrm{UV} / \mathrm{V}$ is diode array spectrophotometer with a time resolution of $100 \mathrm{~ms}$. Samples were excited using a white-light photoflash (Morris AC Slave $\Pi, 21 \mathrm{~W} \mathrm{~s}^{-1}$ ). Binding of the model compounds was followed spectroscopically using the HP 8543 spectrophotometer and a "Kraayenhoff vessel" enabling simultaneous monitoring and adjustment of $\mathrm{pH}$ and temperature. Initial binding experiments were carried out in $50 \mathrm{mM}$ phosphate buffer $\mathrm{pH} 7$, and in $50 \mathrm{mM}$ phosphate plus $50 \mathrm{mM}$ boric acid, $\mathrm{pH} 9$, at temperatures between $25^{\circ} \mathrm{C}$ and $5{ }^{\circ} \mathrm{C}$. Experiments to determine the binding affinity for TMpCA and to study the photoactivity of the non-covalent adduct were carried out at $-20^{\circ} \mathrm{C}$ in $50 \mathrm{mM}$ phosphate buffer, $20 \%$ glycerol, $\mathrm{pH} 7$, at $-10^{\circ} \mathrm{C}$ and $-15^{\circ} \mathrm{C}$.

Experiments at $77 \mathrm{~K}$ were performed in $10 \mathrm{mM}$ phosphate buffer, $67 \%$ glycerol, $\mathrm{pH} 7$ in a Perkin Elmer Lambda UV/Vis spectrophotometer, equipped with a liquid nitrogen cryostat. To investigate photoactivation, the protein sample was transiently illuminated with a blue LED $(470 \mathrm{~nm})$.

\section{Results}

\section{Spectral tuning of covalently attached chromophores}

We reconstituted both WT PYP, and the E46Q derivative, with the native PYP chromophore, i.e. 4-hydroxy-cinnamic acid, and the three derivatives shown in Fig. 1(a), resulting in the proteins
WT-pCA, WT-locked, WT-fer, WT-sin, E46Q-pCA, E46Qlocked, E46Q-fer and E46Q-sin. Both proteins could bind all four chromophores in a $1: 1$ stoichiometry with apo-PYP, as was evident from both mass spectrometry and UV/Vis analysis (data not shown). For WT PYP, these spectra match those in ref. 3. With one methoxy substituent at the meta-position, a red-shift of $15 \mathrm{~nm}$ is observed, and with two methoxy substituents, an even larger red-shift of $40 \mathrm{~nm}$. In WT-sin at $\mathrm{pH} 8$, a substantial amount of a $\mathrm{pB}_{\text {dark }}$-like species with a protonated chromophore is seen, with an absorption maximum at $362 \mathrm{~nm}$ (Fig. 2(a), see also below and Table 1). The $\mathrm{pB}_{\text {dark }}$ state is formed in the dark at low $\mathrm{pH}$, but does resemble the light-induced state $\mathrm{pB} .^{5,7,36,37}$ E46Q PYP was also reconstituted with all four chromophores, resulting in farther-red absorbing species (see Fig. 2(b)). The same trend can be seen as in WT PYP: locked chromophore results in a narrower absorption peak, with only a small wavelength shift (to $453 \mathrm{~nm}$, i.e. a small blue-shift as compared to $p$-coumaric acid). Ferulic acid results in a red-shift of $20 \mathrm{~nm}$. Sinapinic acid shows the largest red-shift: the combination E46Q-sin has an absorption maximum at $495 \mathrm{~nm}$. resulting in an orange protein. Here, the change of one residue in the protcin plus the addition of two methoxy groups to the
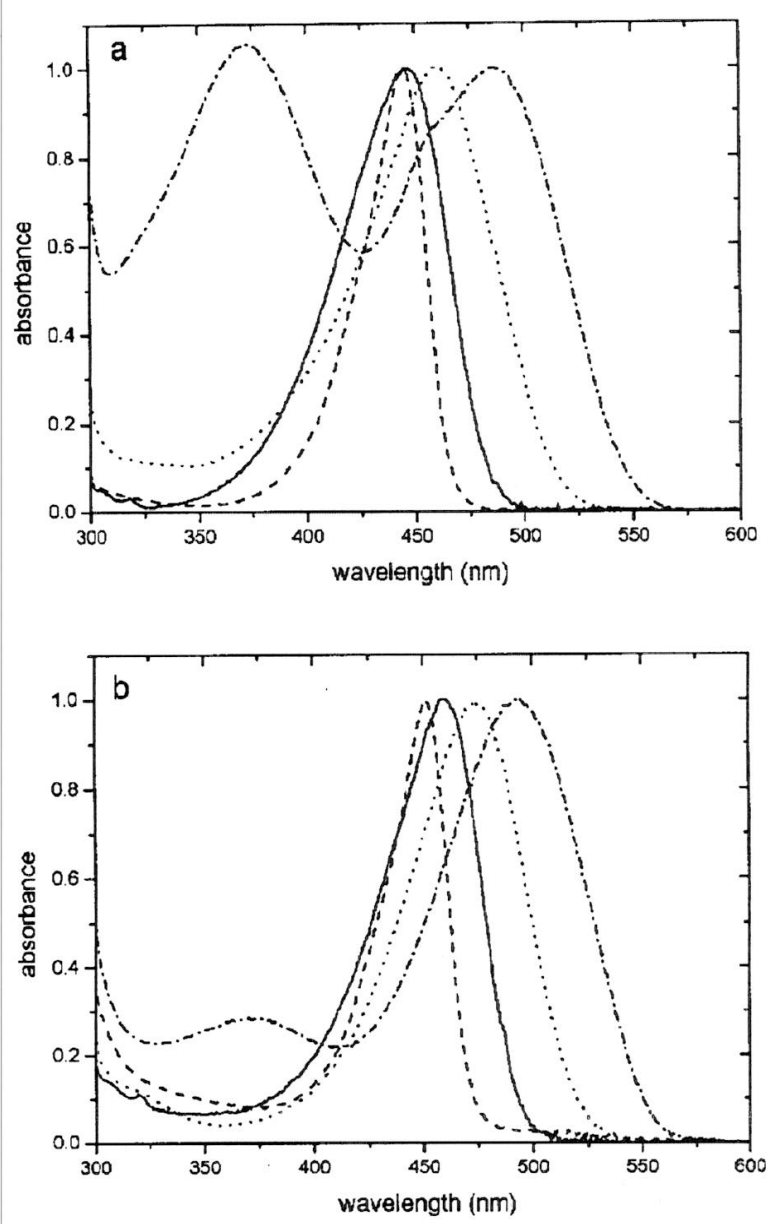

Fig. 2 Normalized UV/Vis absorption spectra of PYP hybrids: (a) WT PYP apoprotein, (b) E46Q PYP apoprotein; pCA (-), locked $(--)$. fer $(\cdots), \sin (\cdots)$. Spectra of protein reconstituted with different chromophores were taken in the dark, in $50 \mathrm{mM}$ phosphate buffer, $\mathrm{pH} 7.5$. 
Table 1 Spectral characteristics of systems used in this study ${ }^{2}$

\begin{tabular}{|c|c|c|c|}
\hline System & $\begin{array}{l}\text { Absorption maximum } \\
\text { (protonated/deprotonated) } / \mathrm{nm}\end{array}$ & $\mathrm{p} K_{\mathrm{a}}(n \text {-value })^{b}$ & $\begin{array}{l}\text { Fluorescence emission } \\
\text { maximum } / \mathrm{nm}\end{array}$ \\
\hline WT-pCA & $355 / 446$ & $2.7(1.9)$ & 492 \\
\hline WT-locked & $370 / 443$ & ND & 464 \\
\hline WT-fer & $417 / 461$ & 3.5 & 526 \\
\hline WT $-\sin$ & $380 / 486$ & $8.7(0.82)$ & 547 \\
\hline $\mathrm{E} 46 \mathrm{Q}-\mathrm{pCA}$ & $360 / 460$ & 5.3 & 499 \\
\hline E46Q-locked & $\mathrm{ND} / 453$ & ND & 486 \\
\hline E46Q-fer & $\mathrm{ND} / 473$ & ND & 529 \\
\hline $\mathrm{E} A 6 \mathrm{Q}-\sin$ & $375 / 495$ & $7.9(0.79)$ & 550 \\
\hline Sinapinic acid & $306 / 355$ & $9.6(0.86)$ & ND \\
\hline TMPCA & $330 / 385$ & 8.5 & ND \\
\hline TM7HC & $362 / 421$ & ND & ND \\
\hline C69G-TMpCA & $-/ 435$ & 6 & ND \\
\hline
\end{tabular}

a ND: not determined. ${ }^{b} n$-value: measure for the steepness of the $\mathrm{pH}$-transition.

chromophore results in a wavelength shift of $50 \mathrm{~nm}$. Although the effects of mutation and chromophore derivative are additive, the size of the shifts resulting from the different chromophores do differ between the wild type and the E46Q protein: the E46Q mutation by itself results in a shift of $682 \mathrm{~cm}^{-1}$, in WT, the sinapinic acid chromophore results in a shift of $1845 \mathrm{~cm}^{-1}$, whereas in $\mathrm{E} 46 \mathrm{Q}$, the sinapinic acid chromophore results in a shift of $1537 \mathrm{~cm}^{-1}$. The total shift from WT-pCA to E46Q-sin is $2220 \mathrm{~cm}^{-1}$. Also note that in $\mathrm{E} 46 \mathrm{Q}-\mathrm{sin}$, there is less $\mathrm{pB}_{\mathrm{dark}}$ formed at $\mathrm{pH} 8$, as compared to WT-sin (see also below).

\section{pH titration of covalently attached chromophores}

To study the formation of $\mathrm{pB}_{\text {dark }}$, as described above, we measured the $\mathrm{pH}$ dependence of ground state spectra of the free sinapinic acid, WT-sin and E46Q-sin (see Fig. 3). In all three cases, the clear isosbestic points obtained indicate the involvement of a two-state transition. We determined the $\mathrm{p} K_{\mathrm{a}}$ values for protonation of the phenolic oxygen in these compounds by fitting the $\mathrm{pH}$ dependent absorption to the Henderson-Hasselbalch equation. The results are shown in the right panels of Fig. 3. The $p K_{a}$ value for the free sinapinic acid $\left(\mathrm{p} K_{\mathrm{a}}=9.6\right)$ differs from the $\mathrm{p} K_{\mathrm{a}}$ value of the model thio-ester of sinapinic acid given in ref. $3\left(\mathrm{p} K_{3}=8.7\right)$, indicating that the thioesterification stabilizes the negative charge on the phenolic oxygen atom of the chromophore. For WT'-sin we found a $\mathrm{pK}$ of 8.7 , indicating that covalent binding of the chromophore to the protein does not provide extra stabilization of the negative charge. Surprisingly, in the combination E46Q sin, the $\mathrm{p} K_{3}$ has decreased almost $1 \mathrm{pH}$ unit, to 7.9 , i.e. it lies in between the $\mathrm{pK}_{\mathrm{a}}$ of $\mathrm{E} 46 \mathrm{Q}-\mathrm{pCA}$ and WT-sin. Apparently, the E46Q mutation stabilizes the (extra) negative charge on the phenolic oxygen. Another surprising finding is the low $n$-value in these titrations, as indicated by its steepness. In all three cases, the $n$-value was $0.8-0.9$, whereas in WT-pCA, an $n$-value of 1.9 is found. The lower $n$-yalue indicates that the hydrogenbonding network, of which the phenolic oxygen is part, has been (partly) disrupted in the two PYP hybrids that contain sinapinic acid as a chromophore. Surprisingly, in the variants with the sin-chromophore, no significant photocycle activity was observed upon excitation. Possibly, the two methoxy groups "anchor" the chromophore in the protein, in such a way that the photocycle can not be initiated. However, the different charge distribution, as
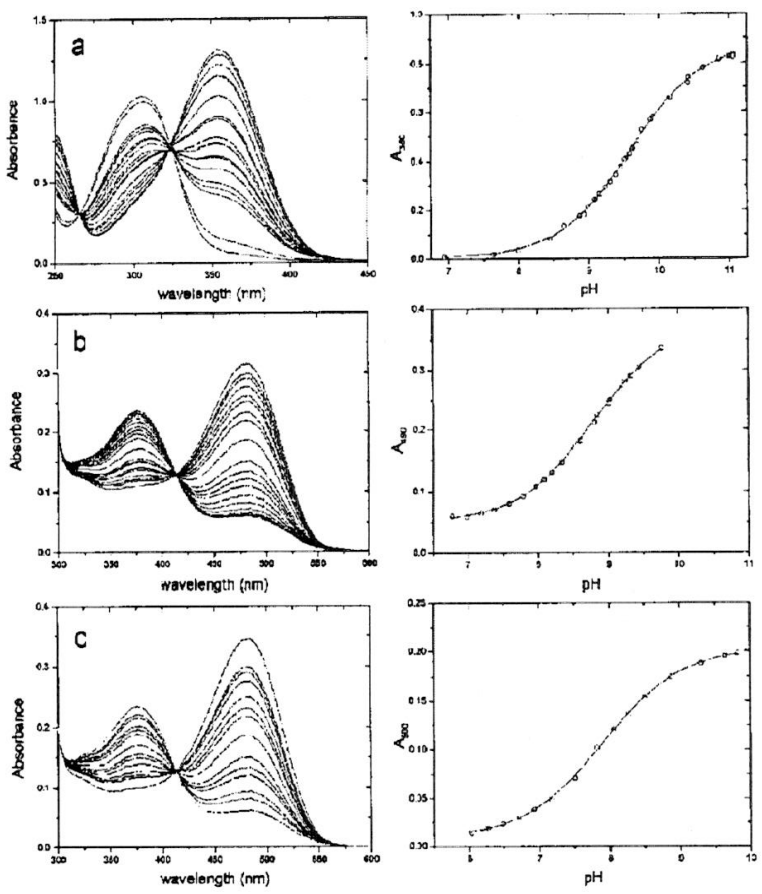

Fig. $3 \mathrm{pH}$ titration of free and protein-bound sinapinic acid. Spectra were measured as a function of $\mathrm{pH}$ in the dark after adding small aliquots of concentrated $\mathrm{HCl}$ or $\mathrm{NaOH}$. (a) Free acid in solution, (b) WT PYP-sin, (c) E46Q PYP-sin. Left-hand panels: absorption spectra; right-hand panels: absorbance at long-wavelength peak versus $\mathrm{pH}(\mathrm{O})$, and the fit of the data according to Henderson-Hasselbalch ( $\longrightarrow$. From this, $\mathrm{p} K_{\mathrm{a}}$ values of $9.6(0.86), 8.7(0.82)$ and $7.9(0.79)$ were calculated for (a). (b) and (c) respectively (values between parentheses are the $n$-values).

suggested by the altered $\mathrm{p} K$ values, may also play an important role, since charge movement upon electronic excitation was shown to play an important role in PYP activation. ${ }^{38,39}$

Model compound synthesis for removal of the PYP-chromophore covalent bond

The thiomethyl model compounds TMpCA and TM7HC were successfully synthesized and purified, as judged from NMR and 
mass spectrometry analysis (not shown). The absorption spectra of both compounds are shown in Fig. 4. TMpCA shows an absorption maximum at $330 \mathrm{~nm}$ at low $\mathrm{pH}$, where the phenolic oxygen is protonated. Its deprotonated form absorbs at $385 \mathrm{~nm}$. This shows that the ester linkage does indeed red-shift the absorption maximum when compared to the free acid. ${ }^{3}$ The $\mathrm{p} K_{\mathrm{a}}$ of the phenolic oxygen was determined to be 8.5 , very similar to the $\mathrm{p} K_{\mathrm{a}}$ found in free 4-hydroxy-cinnamic acid; ${ }^{3}$ apparently, the thioesterification does not influence the $\mathrm{p} K_{\mathrm{a}}$ of this chromophore, in contrast to sinapinic acid, as described above. TM7HC has absorption maxima at $362 \mathrm{~nm}$ and $421 \mathrm{~nm}$, for the protonated and deprotonated form, respectively.

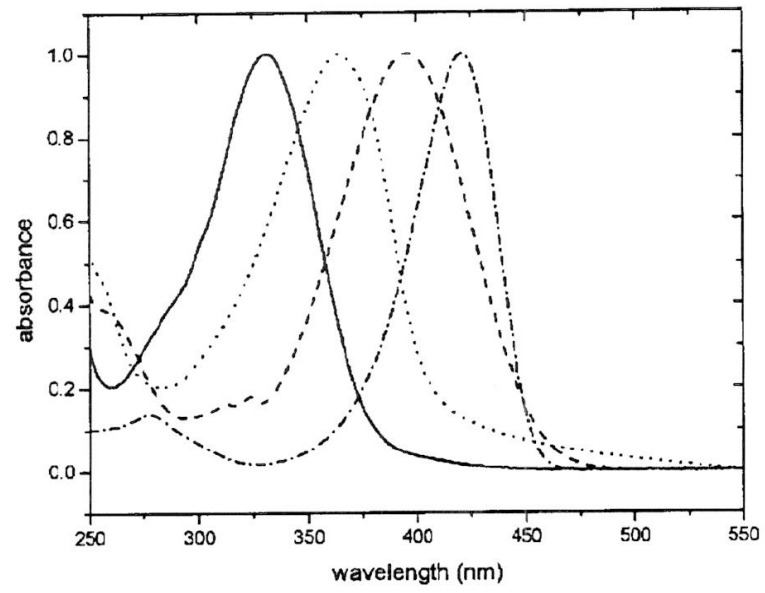

Fig. 4 Absorption spectra of chromophore model compounds, taken in the dark at room temperature. TMpCA, pH $5(-)$, TMpCA, pH 10 $(--)$, TM7HC, pH $5(\cdots)$, TM7HC, pH $10(\cdots)$.

The extinction coefficient of TmpCA was determined using high-pH hydrolysis of the thioester. After hydrolysis its absorbance was compared to the absorbance of free 4-hydroxy-cinnamic acid. Accordingly, the extinction coefficient was determined for its protonated form $\left(\varepsilon_{330}=22 \mathrm{mM}^{-1} \mathrm{~cm}^{-1}\right)$ and for its deprotonated form $\left(\varepsilon_{385}=34 \mathrm{mM}^{-1} \mathrm{~cm}^{-1}\right)$.

\section{Non-covalent binding of chromophore model compounds to $\mathrm{C} 69 \mathrm{G}$ PYP}

To study the importance of the covalent linkage of the chromophore to apo-PYP, we constructed PYP mutants that lack the single cysteine, i.e. the $\mathrm{C} 69 \mathrm{~A}$ and $\mathrm{C} 69 \mathrm{G}$ mutant proteins, and tested complexation of the model compounds and the free acids with these proteins. The C69A protein does not bind TMpCA, nor any of the other available chromophores, at any of the conditions tested (see also below). The model compound TMpCA is shown to complex with the $\mathrm{C} 69 \mathrm{G}$ protein, but only at low temperatures. As seen in Fig. 5, complexation results in tuning of the absorbance maximum, resulting in a maximum at $435 \mathrm{~nm}$, a wavelength maximum close to WT PYP. At room temperature, no absorption at $435 \mathrm{~nm}$ is seen, but upon lowering the temperature to $-20^{\circ} \mathrm{C}$, the absorption at $435 \mathrm{~nm}$ significantly increases, indicating temperature-dependent complexation of TMpCA with C69G protein. The absorption maximum of the chromophore protein complex was $435 \mathrm{~nm}$, regardless if the experiment was

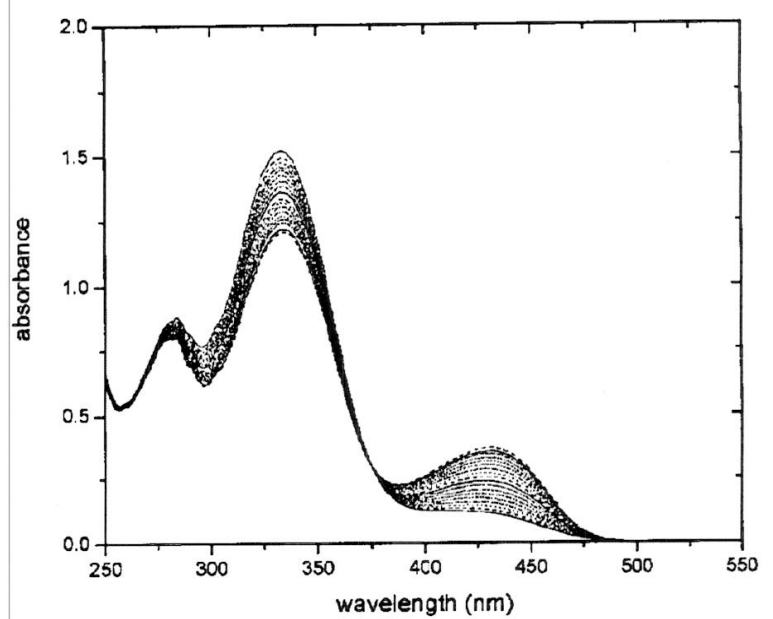

Fig.5 Temperature dependence of TMpCA-binding to apo-PYP. Spectra were taken in the dark, at temperatures between $25^{\circ} \mathrm{C}$ and $-20^{\circ} \mathrm{C}$. At decreasing temperature, absorption at $330 \mathrm{~nm}$ decreased, whereas absorption at $435 \mathrm{~nm}$ increased.

performed at $\mathrm{pH} 7$ or $\mathrm{pH} 9$, suggesting that only the deprotonated chromophore can complex with the protein (see also below). The extinction coefficient of the bound chromophore was determined by comparing the absorbance of same amounts of chromophore in buffer and in the presence of C69G PYP. By comparing the difference in absorbance at $330 \mathrm{~nm}$ and the absorbance at $435 \mathrm{~nm}$, $\varepsilon_{435 ; \text { bound) }}$ was determined to be 1.75 times $\varepsilon_{330(\text { free) }}( \pm 0.03$, averaged over 3 measurements), resulting in an extinction coefficient for the non-covalently bound chromophore $\varepsilon_{4: 5 \text { (bound) }}=40 \mathrm{mM}^{-1} \mathrm{~cm}^{-1}$. This value is only slightly smaller than the extinction coefficient of WT PYP, which equals $45.5 \mathrm{mM}^{-1} \mathrm{~cm}^{-1}$. $^{\text {to }}$ The affinity of TMpCA for C69G PYP was determined by titration of a known amount of protein with small aliquots of the chromophore. Results are shown in Fig. 6; by fitting the titration curve, affinity constants of $90 \mu \mathrm{M}$ and $75 \mu \mathrm{M}$ were found at $-5{ }^{\circ} \mathrm{C}$ and $-10^{\circ} \mathrm{C}$, respectively. A pH titration experiment shows that the protein surroundings stabilize the deprotonated form of the bound chromophore; in solution, the $\mathrm{p} K_{\mathrm{a}}$ is 8.5 , whereas in the protein it is 6 (not shown). This value is intermediate between the values for the chromophore in solution and WT PYP ( $\mathrm{p} K_{\mathrm{a}}=2.7$ ), indicating that the stabilization by the chromophore surroundings is present, but much weaker than in the WT protein. Upon lowering of $\mathrm{pH}$, absorption at $435 \mathrm{~nm}$ decreases, while absorption at $330 \mathrm{~nm}$ increases, suggesting that only the deprotonated chromophore can complex with the $\mathrm{C} 69 \mathrm{G}$ protein pocket. Control experiments to test the specificity of the chromophore-protein interaction were performed using BSA, WT holo-PYP and WT apo-PYP. In none of these cases (aspecific) complexation of the chromophore with the protein, as deduced from absorption changes, could be observed.

\section{Photoactivity in the C69G-TMpCA protein-chromophore complex}

At the conditions where complexation of the model compound with C69G PYP was observed, the possibility of this proteinchromophore complex to undergo a photocycle was tested after excitation with either a short pulse of white light or with blue light from a LED $(470 \mathrm{~nm})$, and after prolonged illumination with 

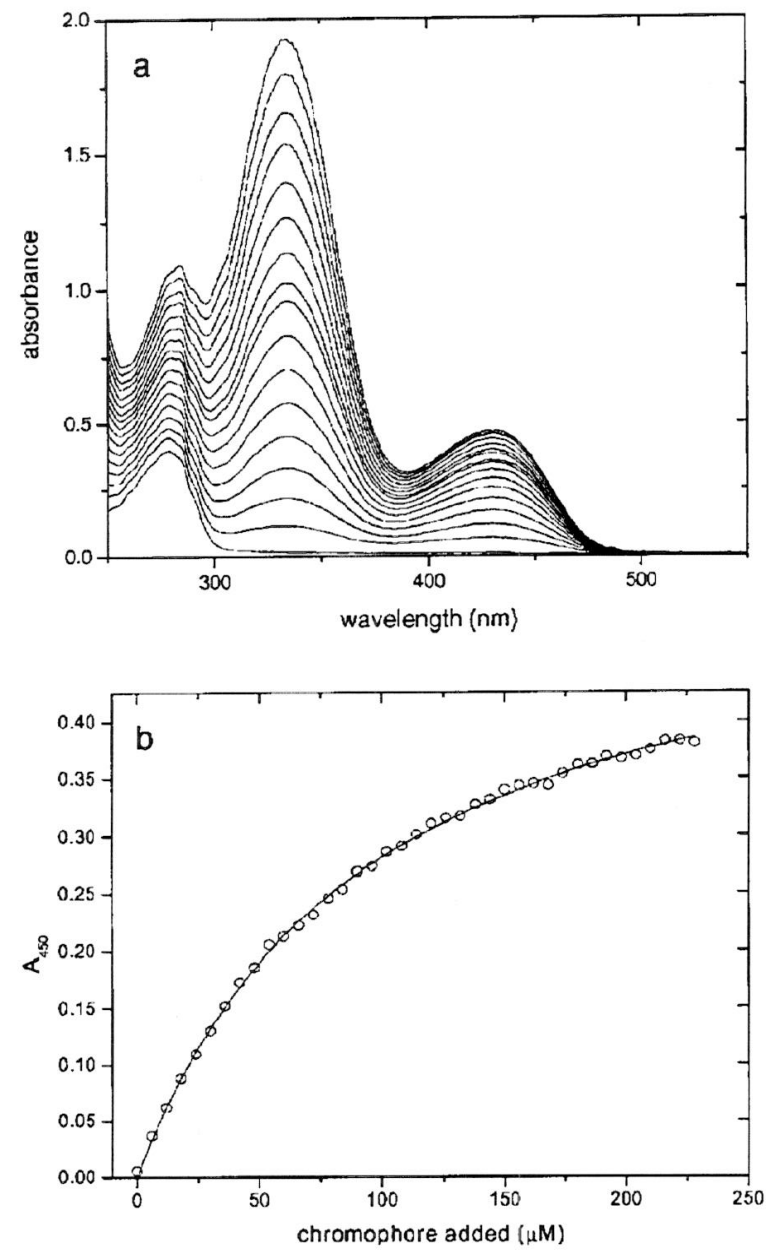

Fig. 6 Titration of C69G PYP with TMpCA. Small aliquots of trans-TMpCA in DMF were added to the $\mathrm{C} 69 \mathrm{G}$ protein in $50 \mathrm{mM}$ phosphate buffer, $20 \%$ glycerol, $\mathrm{pH} 7$. The titration was carried out in the dark, at $-5^{\circ} \mathrm{C}$. Open circles represent the measured absorption, the solid line represents the fit.

the blue LED. After short excitation, or illumination for several minutes, no changes were seen in the spectrum of the pigment. Only after illumination for at least $10 \mathrm{~min}$, a small irreversible decrease was observed in the absorbance of the main absorption peak at $435 \mathrm{~nm}$. Simultaneous formation of a photoproduct, however, was not observed, nor was there recovery of the bleached peak. The photochemistry in this pigment was further studied at low, i.e. liquid nitrogen, temperatures $(77-80 \mathrm{~K})$. Spectra of a C69G PYPTMpCA glycerol glass were taken both in the dark and after a 3 minute illumination. The result is shown in Fig. 7: the dark spectrum of the pigment is not affected by the low temperature. A light-induced bleach of the ground state, albeit relatively small, is observed. The narrowness of the bleached band (19 nm FWHM) and the structure at the edges possibly indicate the formation of (a) species with a maximum close to that of the ground state, but with a smaller extinction coefficient. Furthermore, changes in the UV region around $350 \mathrm{~nm}$ are visible. The red-shifted product $\mathrm{PYP}_{\mathrm{B}}{ }^{41}$ is not readily observed.

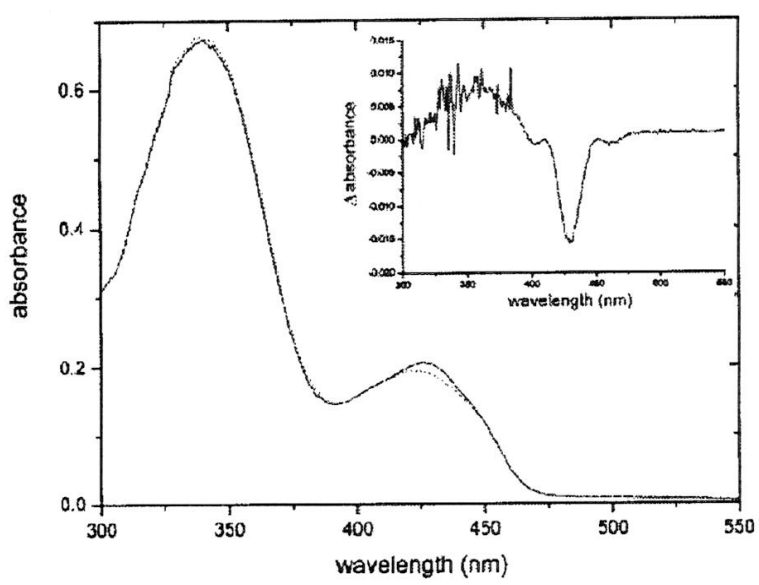

Fig. 7 Photoactivity in the $699 \mathrm{G}-\mathrm{TMpCA}$ pigment at $77 \mathrm{~K}$. UV/ $/ \mathrm{is}$ spectra were measured before (-) and after (--) 3 minute illumination with blue light. The inset shows the light - dark difference spectrum.

\section{Discussion}

Spectral tuning and $\mathrm{p} K_{\mathrm{a}}$ value of covalently attached chromophores

To study the influence of both chromophore and protein modification on the color tuning of PYP, we constructed PYP variants in which the E46Q protein was reconstituted with either the native pCA chromophore, or the analogs 7-hydroxy-coumarin-3carboxylic acid, ferulic acid and sinapinic acid. Both the mutation and the inclusion of methoxy groups on the chromophore, result in a red-shift in the absorption spectrum of the respective proteins. In the combination $\mathrm{E} 46 \mathrm{Q}-$ sin, this shift is so large that it results in a protein that has an orange color instead of yellow. This can be explained by the fact that the electron-donating methoxy groups result in more negative charge in the conjugated $\pi$-system of the chromophore. There are two surprising findings regarding this E46Q--sin PYP variant: (i) it has a lower $\mathrm{p} K_{\mathrm{a}}$ for protonation of the phenolic oxygen of the chromophore than the WT-sin protein, indicating more stabilization of the negative charge on the oxygen in this variant. (ii) The proteins containing a sinapinic acid chromophore are not able to undergo a photocycle upon excitation. The increased (approximately 10-fold compared to PCA in E46Q PYP) quantum yield for fluorescence of this derivative supports this observation. Possible reasons are either the changed charge distribution and/or steric hindrance because of the methoxy groups on the chromophore. Quantum nechanical calculations do not show great variations in the charge distribution close to the $\mathrm{C}=\mathrm{C}$ double bond of the chromophore, favoring the explanation of steric hindrance (e.g. between one of the methoxy groups and Tyr-42, see also ref. 42) as cause of the impaired photoisomerization in this protein (results not shown). Summarizing. we have shown that the absorption spectrum of PYP can be tuned to the red using electron-donating substituents (methoxy groups) on the aromatic ring of the chromophore, as expected, and as could be shown in quantum mechanical calculations. The E46Q mutation itself also results in a redshift of the absorption spectra. When these two (mutation and chromophore modification) were combined, it was shown that the red-shifts are additive, resulting in a total shift of $50 \mathrm{~nm}$. The E46Q - sin variant shows an unexpectedly lowered $\mathrm{p} K_{3}$. Note, 
however, that this $\mathrm{p} K_{\mathrm{a}}$ can be influenced both by protein stability and charge distribution on the chromophore. ${ }^{43}$ However, because of the relative high $\mathrm{p} K_{\mathrm{a}}$ in the variants described here and the reported small perturbation in the structure of PYP with a comparable chromophore analog ${ }^{42}$ it is likely that these $\mathrm{p} K_{\mathrm{a}}$ values describe the $\mathrm{p} K_{\mathrm{a}}$ of the chromophore in a folded protein.

\section{Non-covalent binding of chromophore model compounds to $\mathrm{C} 69 \mathrm{G}$ PYP}

We synthesized chromophore model compounds that are thiomethylesters of the respective free acids, i.e. 4-hydroxycinnamic acid and 7-hydroxy-coumarin-3-carboxylic acid. In the latter, the vinyl bond that isomerizes in 4-hydroxy-cinnamic acid is effectively locked in its trans configuration. The spectra of these compounds, both in neutral and in deprotonated form, are red-shifted with respect to the spectra of the free acids, showing the importance of the ester linkage in the tuning of these chromophores. When compared to the absorption maximum of denaturated PYP, the absorption maxima of both neutral and deprotonated TMPCA are blue-shifted by $\sim 20 \mathrm{~nm}$, showing that in the denaturated state, there are still protein-chromophore interactions that red-shift the absorption maxima. Furthermore, the spectrum is also red-shifted when compared to the methylester of pCA, that has an oxygen atom instead of a sulfur atom (absorption maxima at $310 \mathrm{~nm}$ and $360 \mathrm{~nm}$ for the protonated and deprotonated form, respectively; result not shown). This shows that the conjugated light-absorbing system includes the sulfur atom at this position, which is consistent with quantum mechanical calculations described in ref. 4 . The $\mathrm{p} K_{2}$ of protonation of the phenolic oxygen of the chromophore is very close to the one in the denatured protein or in the free acid, i.e. 8.5. We used these model compounds to study the importance of noncovalent binding on photoactivation in PYP variants in which the chromophore-binding cysteine has been replaced by either an alanine or a glycine residue. In the $\mathrm{C} 69 \mathrm{~A}$ protein, no binding of any of the model compounds was observed, presumably because of steric hindrance between the alanine side-chain and the methyl group of the chromophores (see Fig. 1). Non-covalent binding, followed spectrally, was only observed when the chromophore model compound TMpCA was used in combination with $\mathrm{C} 69 \mathrm{G}$ PYP, i.e. upon isosteric replacement. Complexation resulted in a large red-shift of the absorption maximum to $435 \mathrm{~nm}$, remarkably close to the absorption maximum at $446 \mathrm{~nm}$ in WT PYP. As opposed to the non-covalent binding of chromophores in other photoreceptor proteins, however, the complexation in this case was very weak, with a $K_{\mathrm{d}}$ in the $10-100 \mu \mathrm{M}$ range. The temperaturedependence of the complexation, i.e. more complexation at low temperatures, indicates that this process is enthalpy-driven. The complexation shows that the hydrogen bonds from Glu46 to the chromophore hydroxyl group and from the chromophore carbonyl to the cysteine backbone nitrogen are sufficient to keep the chromophore in the binding pocket, at least in the ground state of the protein. However, although binding can take place in the absence of a covalent linkage between the chromophore and the protein backbone, the photoactivity of the resulting pigment is strongly impaired. At temperatures from $0^{\circ} \mathrm{C}$ to $-20^{\circ} \mathrm{C}$, short blue-light excitation does not result in observable spectral changes, implying a very low--if any-quantum yiek for photochemistry. Note that the TmpCA chromophore free in aqueous solution has been shown before not to isomerize (efficiently) upon illumination. ${ }^{44}$ Apparently, in the WT protein. the protein surroundings make efficient isomerization possible. Only after prolonged illumination, a small decrease in absorbance of the main absorption peak is observed. However, the absorbance does not recover after incubation in the dark, not even if the temperature is raised to $20^{\circ} \mathrm{C}$ and then subsequently is decreased again. Because the experiment has to be performed with an excess amount of TMPCA (to saturate the binding site; see above), this implies that the chromophore does remain in the active site after excitation, but cannol return to its ground state. The chromophore may have undergone trans-cis isomerization, but the absence of the covalent linkage prevents the following steps in the photocycle. In wild type PYP, at temperatures below $93 \mathrm{~K}$, the photocycle is blocked ${ }^{45}$ after formation of the red-shifted intermediate $I_{0}$ or, in a branched pathway, the slightly blue-shifted intermediate $\mathrm{PYP}_{\mathrm{H}}$ and the red-shifted intermediate $\mathrm{PYP}_{\mathrm{B}}{ }^{4}{ }^{41}$ Low-temperature photocycle intermediates have been studied using FTIR, where $\mathrm{PYP}_{\mathrm{B}}$ and $\mathrm{PYP}_{\mathrm{L}}$ were shown to be formed in parallel pathways, and to differ in structure. ${ }^{45}$ Both intermediates were also analyzed in (low temperature) crystallographic studies. ${ }^{47,48}$ These studies showed that $\mathrm{PYP}_{\mathrm{B}}$ and $\mathrm{PYP}_{\mathrm{H}}$ have a chromophore in the cis configuration. The exact difference between the two intermediates conld not be shown, but the studies indicated that all changes are restricted to the region around the $\mathrm{C} 2=\mathrm{C} 3$ bond. We studied if an intermediate similar to one of these can be formed in the $\mathrm{C} 69 \mathrm{G}$ PYP-TMpCA pigment after excitation at $77 \mathrm{~K}$. Indeed a slightly blue-shifted intermediate, possibly $\mathrm{PYP}_{\mathrm{H}}$, can be observed. None of the absorbance changes indicate formation of the red-shifted in termediate PYP ${ }_{B}$, absorbing at $489 \mathrm{~nm}$ in WT PYP. Apparently, the lack of a covalent linkage from the chromophore to the protein backbone prevents formation of this specific intermediate (and the subsequent branched intermediate $\mathrm{PYP}_{\mathrm{BL}}$ ). The small changes at the red edge of the bleach, i.e. around $460 \mathrm{~nm}$, may indicate the formation of a $\mathrm{PYP}_{\mathrm{L}}$-like species. ${ }^{41}$ Furthermore, increased absorption in the $\mathrm{UV}$ region is visible, with a maxinum at $355 \mathrm{~nm}$, suggesting formation of a pB-like (protonated) species. Apparently, in this complex, transitions are possible at temperatures where in WT PYP these are blocked, presumably because the chromophore has more freedom to move. However, only a very small fraction of molecules is bleached, even after prolonged illumination.

\section{Conclusions}

During the PYP photocycle, the hydrogen bonds between the chromophore and the protein backbone, i.e. from Tyr42 and Glu46 to the hydroxyl group of the chromophore and from the chromophore carbonyl group to the nitrogen atom of Cys69, are of paramount importance. Recently, through ultrafast studies on PYP, the importance of these hydrogen bonds has been stressed again. It was shown that already in the very early stages of the photocycle, Glu46 starts "pulling" on the chromophore: The hydrogen bond first weakens in the excited state, then gets stronger during $I_{0}$ and $p R$ formation, ${ }^{49,50}$ but finally breaks upon formation of $\mathrm{pB}$. The carbonyl group that in the ground state hydrogen bonds to cysteine, rotates upon photo-activation, thereby trausiently breaking the hydrogen bond. Also from an 
optoacoustic study, ${ }^{51}$ chromophore 'contraction' directly resulting from photoisomerization, was observed upon $\mathrm{pR}$ formation.

We conclude that the covalent linkage between the chromophore and the protein backbone is of high importance for the functional activity of the protein in vitro. This in contrast to other photosensor proteins with an isomerizable chromophore, that can function without a non-covalently bound chromophore. Presumably, the delicate in terplay between photoisomerization and changes in the hydrogen bonding network needed in the PYP photocycle requires a covalently linked chromophore.

\section{Acknowledgements}

We thank Alex Ter Beek and Robert Cordfunke for help in the early stages of the project, Louis Hartog and Toh Kee Chua for expert technical assistance and Jocelyne Vreede for the quantum mechanical calculations. Wouter Hoff is acknowledged for critical reading of the manuscript and valuable suggestions.

\section{References}

1 D. Man, W. Wang, G. Sabehi. L. Aravind, A. F. Post, R. Massana E. N. Spudich. J. L. Spudich and O. Beja, Diversification and spectral tuning in marine proteorhodopsins, EMBO J., 2003, 22, 1725

2 L. Ren, C. H. Martin, K. J. Wise, N. B. Gillespie, H. Luecke, J. K. Lanyi, J. L. Spudich and R. R. Birge, Molecular mechanism of spectra tuning in sensory rhodopsin II. Biochemistry, 2001, 40, 13906.

3 A. R. Kroon, W. D. Hoff, H. P. Fennema, J. Crijzen, G. J. Koomen, J. W. Verhoeven, W. Crielaard and K. J. Hellingwerf, Spectral tuning, fluorescence, and pholoactivity in hybrids of photouctive yellow protein, reconstituted with native or modified chromophores, J. Biol. Chem., 1996, 271, 31949.

4 M. Yoda, H. Houjou, Y. Inoue and M. Sakurai, Spectral tuning of photoactive yellow protein. Theoretical and experimental analysis of medium effects on the absorption spectrum of the chromophore, J. Phys. Chem. B, 2001, 105,9887.

5 T. E. Meyer, Isolation and characterization of soluble cytochromes, ferredoxins and other chromophoric proteins from the halophilic phototrophic bacterium Ectothiorhodospira halophila, Biochim. Biophys. Acta, 1985, 806, 175.

6 W. D. Hoff, I. H. van Stokkum, H. J. van Ramesdonk, M. E. van Brederode, A. M. Brouwer, J. C. Fitch, T. E. Meyer, R. van Grondelle and K. J. Hellingwerf, Measurement and global analysis of the absorbance changes in the photocycle of the photoactive yellow protein from Ecto thiorhodospira halophila, Biophys. J., 1994, 67, 1691.

7 T. E. Meyer, E. Yakali, M. A. Cusanovich and G. Tollin, Properties of a water-soluble, yellow protein isolated from a halophilic phototrophic bacterium that has photochemical activity analogous to sensory rhodopsin, Biochemistry, 1987, 26, 418 .

8 M. Baca, G. E. Borgstahl, M. Boissinot, P. M. Burke, D. R. Williams, K. A. Slater and E. D. Getzoff, Complete chemical structure of photoactive yellow protein: novel thioester-linked 4-hydroxycinnamyl chromophore and photocycle chemistry, Biochemistry, 1994, 33, 14369.

9 W. D. Hoff, P. Dux, K. Hard, B. Devreese, I. M. Nugteren-Roodzant, W. Crielaard, R. Boelens, R. Kaptein, J. van Beeumen and K. J. Hellingwerf, Thiol ester-linked p-coumaric acid as a new photoactive prosthetic group in a protein with rhodopsin-like photochemistry, Biochemistry, 1994, 33, 13959.

10 J. J. Van Beeumen, B. V. Devreese, S. M. Van Bun, W. D. Hoff, K. J. Hellingwerf, T. E. Meyer, D. E. McRee and M. A. Cusanovich, Primary structure of a photoactive yellow protein from the phototrophic bacterium Ectothiorhodospira halophila, with evidence for the mass and the binding site of the chromophore, Protein Sci., 1993, 2, 1114 .

11 G. E. Borgstahl, D. R. Williams and E. D. Getzoff, $1.4 \AA$ structure of photoactive yellow protein, a cytosolic photoreceptor: unusual fold active site, and chromophore, Bicchemistry, 1995, 34, 6278.
12 R. Kort. H. Yonk, X. Xu, W. D. Hoff, w. Crielaard and K. J. Hellingwerf, Evidence for trans cis isomerization of the p-coumaric acid chromophore as the photochemical basis of the photocycle of photoactive yellow protein, FEBS Lett., 1996, 382, 73.

13 A. Xie W. D. Hoff, A. R. Kroon and K. J. Hellingwerf, Glu46 donates a proton to the 4-hydroxycinnamate anion chromophore during the photocycle of photoactive yellow protein, Biochemistry, 1996, 35, 14671.

14 N. M. Derix, R. W. Wechselberger, M. A. van der Horst, K. J. Hellingwerf, R. Boelens, R. Kaptein and N. A. van Nuland, Lack of negative charge in the $E 46 \mathrm{Q}$ mutant of photoactive yellow protein prevents partial unfolding of the blue-shifted intermediate, Biochemistry, 2003, 42, 14501

15 U. K. Genick, S. Devanathan, T. E. Meyer, I. L. Canestrelli, E. Williams, M. A. Cusanovich, G. Tollin and E. D. Getzoff, Activo site mutants implicate key residues for control of color and light cycle kinetics of photoactive yellow protein, Biochemistry, 1997, 36, 8 .

16 S. Rajagopal, S. Anderson, V. Srajer, M. Schmidt, R. Pahl and K. Moffat, A structural pathway for signaling in the E46Q mutant of photoactive yellow protein, Structure, 2005, 13, 55 .

17 M. Sugishima, N. Tanimoto, K. Soda, N. Hamada, F. Tokunaga and K. Fukuyama, Structure of photoactive yellow protein (PYP) E46Q mutant at 1.2 A resolution suggests how Glu46 controls the spectroscopic and kinetic characteristics of PYP, Acta Crystallogr., Sect. D: Biol. Crystallogr., 2004, 60, 2305.

18 A. Xie, L. Kelemen. J. Hendriks, B. J. White, K. J. Hellingwerf and W. D. Hoff, Formation of a new buried charge drives a large-amplitude protein quake in photoreceptor activation, Biochemistry, 2001, 40, 1510.

19 R. Kort, W. D. Hoff, M. Van West, A. R. Kroon, S. M. Hoffer, K. H. Vlieg, W. Crielaand. J. J. Van Beeumen and K. J. Hellingwerf, The xanthopsins: a new family of eubacterial blue-light photoreceptors. EMBO J., 1996, 15, 3209 .

20 M. A. van der Horstand and K. J. Hellingwerf, Photoreceptor proteins, "star actors of modern times": a review of the functional dynamics in the structure of representative members of six different photoreceptor families, Acc. Chem. Res., 2004, 37, 13.

21 M. Salomon, J. M. Christie, E. Knieb, U. Lempert and W. R. Briggs, Photochemical and mutational analysis of the FMN-binding domains of the plant blue light receptor, phototropin, Biochemistry, 2000, 39, 9401.

22 S. Crossonand and K. Moffat, Photoexcited structure of a plant photoreceptor domain reveals a light-driven molecular switch, Plant Cell, 2002, 14, 1067.

23 U. Schweiger, J. Tittor and D. Oesterhelt, Bacteriorhodopsin can function without a covalent linkage between retinal and protein, Biochemistry, 1994, 33, 535 .

24 N. Friedman, S. Druckmann, J. Lanyi, R. Needleman, A. Lewis, M. Ottolenghi and M. Sheves, A covalent link between the chromophore and the protein backbone of bacteriorhodopsin is not required for forming a photochemically active pigment analogeus to the wild type, Biochemistry, 1994, 33, 1971.

25 E. A. Zhukovsky, P. R. Robinson and D. D. Oprian, Transducin activation by rhodopsin without a covalent bond to the 11-cis-retinal chromophore, Science, 1991, 251, 558.

26 C. Fankhauser, The phytochromes, a family of red/far-red absorbing photoreceptors, J. Biol. Chem, , 2001, 276, 11453.

27 H. J. Jorissen, B. Quest, A. Remberg, T. Coursin, S. E. Braslavsky, K. Schaffner, N. T. de Marsac and W. Gartner. Two independent, light-sensing two-component systems in a filamentous cyanobacterium, Eur. J. Biochem., 2002, 269, 2662.

28 H. J. Jorissen, B. Quest, I. Lindner, N. Tandeau de Marsac and W. Gartner, Phytochromes with noncovalently bound chromophores: the ability of apophytochromes to direct tetrapyrrole photoisomerization, Photochem. Photobiol, 2002, 75, 554.

29 R. Cordfunke, R. Kort, A. Pierik, B. Gobets, G. J. Koomen, J. W. Verhoeven and $\mathrm{K}$. J. Hellingwerf, Trans/cis $(Z / E)$ photoisomerization of the chromophore of photoactive yellow protein is not a prerequisite for the initiation of the photocycle of this photoreceptor protein, Proc. Natl. Acad. Sci. U. S. A., 1998, 95, 7396

30 Y. Imamoto, T. Ito, M. Kataoka and F. Tokunaga, Reconstitution photoactive yellow protein from apoprotein and p-coumaric acid derivatives, FEBS Lett., 1995, 374, 157.

$31 \mathrm{H}$. Chosrowjan, N. Mataga, Y. Shibata, Y. Imamoto and F. Tokunaga, Environmental effects on the femtosecond-picosecond fluorescence 
dynamics of photoactive yellow protein: Chromophores in aqueous solutions and in protein nanospaces modified by site-directed mutagenesis, J. Phys. Chem. B, 1998, 102, 7695.

32 H. Chosrowjan, S. Taniguchi, N. Mataga, M. Unno, S. Yamauchi, N. Hamada, M. Kumauchi and F. Tokunago, Low-frequency vibrations and their role in ultrafast photoisomerization reaction dynamics of photoactive yellow protein, J. Phys. Chem. B, 2004, 108, 2686

33 P. Changenet-Barret, P. Plaza, M. M. Martin, H. Chosruwjan, S. Taniguchi, N. Mataga, Y. Imamoto and M. Kataoka, Role of arginine 52 on the primary photoinduced events in the PYP photocycle, Chem. Phys. Lett., 2007, 434, 320.

34 J. Hendriks, T. Gensch, L. Hviid, M. A. van Der Horst, K. J. Hellingwerf and J. J. van Thor, Transient exposure of hydrophobic surface in the photoactive yellow protein monitored with Nile Red, Biophys. J., 2002 , $82,1632$.

35 G. Aulin-Erdtmanand and R. Sanden, Contributions to lignin chemistry IX, Acta Chem. Scand., 1968, 22, 1187.

36 C. J. Craven, N. M. Derix, J. Hendriks, R. Boelens, K. J. Hellingwerf and R. Kaptein, Probing the nature of the blue-shifted intermediate of photoactive yellow protein in solution by NMR: hydrogen-deuterium exchange data and $\mathrm{pH}$ studies, Biochemistry, 2000, 39, 14392.

37 W. D. Hoff, I. H. M. Van Stokkum, J. Gural and K. J. Hellingwerf, Comparison of acid denaturation and light activation in the eubacterial blue-light receptor photoactive yellow protein, Biochim. Biophys. ActaBioenergetics, 1997, 1322, 151.

38 L. L. Premvardhan, M. A van der Horst, K. J. Hellingwerf and R. van Grondelle, Stark spectroscopy on photoactive yellow protein, E46Q, and nonisomerizing derivative, probes photo-induced charge motion Biophys. J., 2003, 84, 3226.

39 A. Espagne, P. Changenet-Barret, J. B. Baudin, P. Plaza and M. M. Martin, Photoinduced charge shift as the driving force for the excitedstate relaxation of analogues of the Photoactive Yellow Protein chromophore in solution, J. Photochem. Photobiol., A, 2007, 185, 245.

40 T. E. Meyer, G. Tollin, J. H. Hazzard and M. A. Cusanovich, Photoactive yellow protein from the purple phototrophic bacterium, Ectothiorhodospira halophila. Quantum yicld of photobleaching and effects of temperature, alcohols, glycerol, and sucrose on kinetics of photobleaching and recovery, Biophys. J., 1989, 56, 559.

41 Y. Imamoto, M. Kataoka and F. Tokunaga, Photoreaction cycle of photoactive yellow protein from Ectothiorhodospira halophila studied by low-temperature spectroscopy, Biochemistry, 1996, 35, 14047.
42 D. M. van Aalten, W. Crielaard, K. J. Hellingwerf and L. Joshua-Tor, Structure of the photoactive yellow protein reconstituted with caffeic acid at 1.16 A resolution, Acia Crystallogr., Sect. D: Biol. Crystallogr., $2002, \mathbf{5 8}, 585$

43 T. E. Meycr, S. Devanathan, T. Woo, E. D. Getzoff, G. Tollin and M. A. Cusanovich, Site-specific mutations provide new insights into the origin of $\mathrm{pH}$ effects and alternative spectral forms in the photoactive yellow protein from Halorhodospira halophila, Biochemistry, 2003, 42. 3319.

44 D. S. Larsen, M. Vengris, I. H. van Stokkum, M. A. van der Horst, F. L. de Weerd, K. J. Hellingwerf and R. van Grondelle, Photoisomerization and photoionization of the photoactive yellow protein chromophore in solution, Biophys. J., 2004, 86, 2538.

45 W. D. Hoff, S. L. S. Kwa, R. Van Grondelle and K. J. Hellingwerf, Low-Temperature $\Lambda$ bsorbency and Fluorescence Spectroscopy of the Photoactive Yellow Protein from Ectothiorhodospira Halophila, Photochem. Photobiol., 1992, 56, 529.

46 Y. Imamoto, Y. Shirahige, F. Tokunaga, T. Kinoshita, K. Yoshihara and M. Kataoka, Low-temperature Fourier transform infrared spectroscopy of photoactive yellow protein, Bicchemistry, 2001, 40,8997.

47 R. Kort, K. J. Hellingwerf and R. B. Ravelli, Initial events in the photocycle of photoactive yellow protein, J. Biol. Chem., 2004, 279, 26417.

48 R. Kort, R. B. Ravelli, F. Schotte, D. Bourgeois, W. Criclaard, K. J. Hellingwerf and $M$. Wulff, Characterization of photocycle intermediates in crystalline photoactive yellow protein, Photochem. Photobiol., 2003, 78, 131.

49 M. L. Groot, L. J. van Wilderen, D. S. Larsen, M. A. van der Horst, I. H. van Stokkum, K. J. Hellingwerf and R. van Grondelle, Initial steps of signal generation in photoactive yellow protein revealed with femtosecond mid-infrared spectroscopy, Biochemistry, 2003, 42, 10054.

50 L. J. van Wilderen, M. A. van der Horst, I. H. van Stokkum, K. J. Hellingwerf, R. van Grondelle and M. L. Groot, Ultrafast infrared spectroscopy reveals a key step for successful entry into the photocycle for photoactive yellow protein, Proc. Natl. Acad. Sci. U. S. A., 2006, 103,15050

51 A. Losi, T. Gensch, M. A. van der Horst, K. J. Hellingwerf and S. E. Braslavsky, Hydrogen-bond network probed by time-resolved optoacoustic spectroscopy: photoactive yellow protein and the effect of E46Q and E46A mutations, Phys. Chem. Chem. Phys., 2005, 7, 2229 